\title{
Gas sensing properties of nanocrystalline silicon carbide films
}

\author{
Alexander Semenov ${ }^{1 *} \mathbb{C}$, Anatolii Kozlovskyi², Stanislav Skorik² and Denis Lubov ${ }^{1}$
}

\begin{abstract}
The influence of the air atmosphere on the electrical conductivity of nanocrystalline thin SiC films obtained by method of direct ion deposition on sapphire was studied. Measurements were performed on two series of nc-SiC films with different structure: one series contained mainly 3C-SiC polytype nanocrystals and were denoted as monopolytypic, the second series were a nanoheterostructures based on a mixture of 3C-SiC and 21R-SiC nanocrystals. Gas sensitivity of the films appeared after annealing in vacuum at temperatures above $500 \mathrm{~K}$. Measurements of the gas sensitivity of the films to the air atmosphere at a temperature of $700 \mathrm{~K}$ showed that the resistance increased for 12 times for the monopolytype film, while the heteropolytype film showed an increase of resistance for almost 16 times.

Keywords: Silicon carbide based gas sensors, Nanocrystalline silicon carbide film, Air effect on electrical resistance, Structure effect on air sensitivity
\end{abstract}

\section{Introduction}

In modern developments of semiconductor sensors for detecting and determining of the concentration of gases and gas impurities in the air, layers of metal oxides with an electronic type of conductivity $\left(\mathrm{SnO}_{2}, \mathrm{In}_{2} \mathrm{O}_{3}, \mathrm{ZnO}\right.$, $\mathrm{Fe}_{2} \mathrm{O}_{3}, \mathrm{CuO}, \mathrm{TiO}_{2}$, etc.) are widely used as gas-sensitive sensors $[1,2]$. The principle of operation of such sensors is based on the fact that reversible chemisorption of reducing (e.g. $\mathrm{H}_{2}, \mathrm{CH}_{4}, \mathrm{NH}_{3}, \mathrm{CO}$ ) or oxidizing gases (e.g. $\mathrm{O}_{2}, \mathrm{NO}, \mathrm{NO}_{2}$ ) on their surface is accompanied by a reversible change in the conductivity of the functional layer.

Due to the increased requirements for the stability of sensors under the influence of intense radiation and electromagnetic fields, there is a great problem of search for new functional semiconductor materials for the creation of highly sensitive gas sensors that slightly change their properties over time under hard external influences. One of the promising materials with chemical inertness, resistance to radiation impacts and time stability of properties are materials based on $\mathrm{SiC}$ [3], in particular,

\footnotetext{
*Correspondence: savladi@ukr.net

${ }^{1}$ National Technical University "Kharkiv Polytechnic Institute", 2,

Kyrpychova Str., Kharkiv 61002, Ukraine

Full list of author information is available at the end of the article
}

nanocrystalline $\mathrm{SiC}$ (nc-SiC) films obtained by method of direct deposition of carbon and silicon ions [4]. The technology of growth of nanocrystalline $\mathrm{SiC}$ films is much cheaper than the technology of producing monocrystalline $\mathrm{SiC}$ films, whose gas-sensitive properties have previously been studied [5-7].

Previously, it was found that nc-SiC films containing a single predominant polytype (monopolytype) show the thermoactivation conductivity mechanism, and the films containing a mixture of polytypes (heteropolytype) demonstrate two-channel conductivity mechanism, one of which is based on the tunneling of electrons through the barrier between nanocrystals of different polytypes [8]. Radiation resistance of such films was studied by us earlier [9]. The stability of the electrophysical properties of nc-SiC films in strong magnetic fields at low temperatures was shown in [10]. At the same time, the gas sensitivity of thin films of nanocrystalline $\mathrm{SiC}$ has not been studied.

Therefore, the purpose of this paper was to investigate the dependence of electrical conductivity of thin nanocrystalline $\mathrm{SiC}$ films with different polytype structure on the air atmosphere at certain temperatures. 


\section{Materials and methods}

Two series of thin nc-SiC films with different polytype structure were prepared on sapphire substrates by method of direct deposition of carbon and silicon ions with energy of $100-120 \mathrm{eV}[3,11]$. One series of films contained mainly $3 \mathrm{C}$-SiC-polytype nanocrystals and was denoted as monopolytypic one (MP-nc-SiC), the second series were nanoheterostructures based on a mixture of $3 \mathrm{C}-\mathrm{SiC}$ and 21R-SiC nanocrystals (HP-nc-SiC) [12]. A small excess of silicon in the films caused their electronic conductivity [13]. The sizes of nanocrystals ranged from 5 to $50 \mathrm{~nm}$ [11]. Figure 1 shows atomic-force microscope (AFM) images of films of both series. The film thickness ranged from 100 to $200 \mathrm{~nm}$. For resistive measurements, rectangular contact $\mathrm{Au} / \mathrm{Ni} 7 \times 7 \mathrm{~mm}^{2}$ areas were applied at a distance of $2 \mathrm{~mm}$ between the boundaries contacts. The dependence of the electrical conductivity of the films on the temperature was measured in the range from 300 to $700 \mathrm{~K}$. The effect of the gas atmosphere was determined by comparing the electrical conductivity of films in vacuum and in air under normal pressure at different temperatures. The measurements were carried out in a vacuum unit VUP- 5 by controlled gas inlet into the chamber after pumping to a pressure of $10^{-1} \mathrm{~Pa}$. The gas sensitivity coefficient was estimated by the formula $\mathrm{S}$ $(\%)=\left(\left|R_{g}-R_{a}\right| / R_{a}\right) \times 100 \%$, where $R_{g}$ and $R_{a}$ are the film resistance in the presence and absence of air atmosphere, respectively.

\section{Results and discussion}

Figure 2 shows current-voltage characteristics of thin films of two series (MP-nc-SiC and HP-nc-SiC), measured in weak electric fields $(\mathrm{E}<50 \mathrm{~V} / \mathrm{cm})$ in atmospheric air at temperature $293 \mathrm{~K}$. The current-voltage characteristics for the nc-SiC monopolytype and heteropolytype series of films on sapphire are linear. This means that in weak fields the nanocrystalline $\mathrm{SiC}$ films possess ohmic mechanism of electrical conductivity over the entire voltage range. This behavior of semiconductors in weak electric fields is well known [14]. For the HP-nc-SiC series films, the current value on the current-voltage characteristics was always $3-5$ times higher on average compared to the monopolytype ones at the same size, which may be due to the multi-channel mechanism of conductivity in nanoheterostructures and greater charge mobility in the rhombohedral polytype $21 \mathrm{R}-\mathrm{SiC}$, compared to the $3 \mathrm{C}-\mathrm{SiC}$ cubic polytype. Figure 3 shows current-voltage characteristics of the same series of films measured in vacuum at $\mathrm{p}<10^{-1} \mathrm{~Pa}$ at a temperature of $293 \mathrm{~K}$. Measurements were made both on initial samples and preannealed in vacuum at temperatures of 500 and $700 \mathrm{~K}$ for $10 \mathrm{~min}$. Measurements of the annealed films were

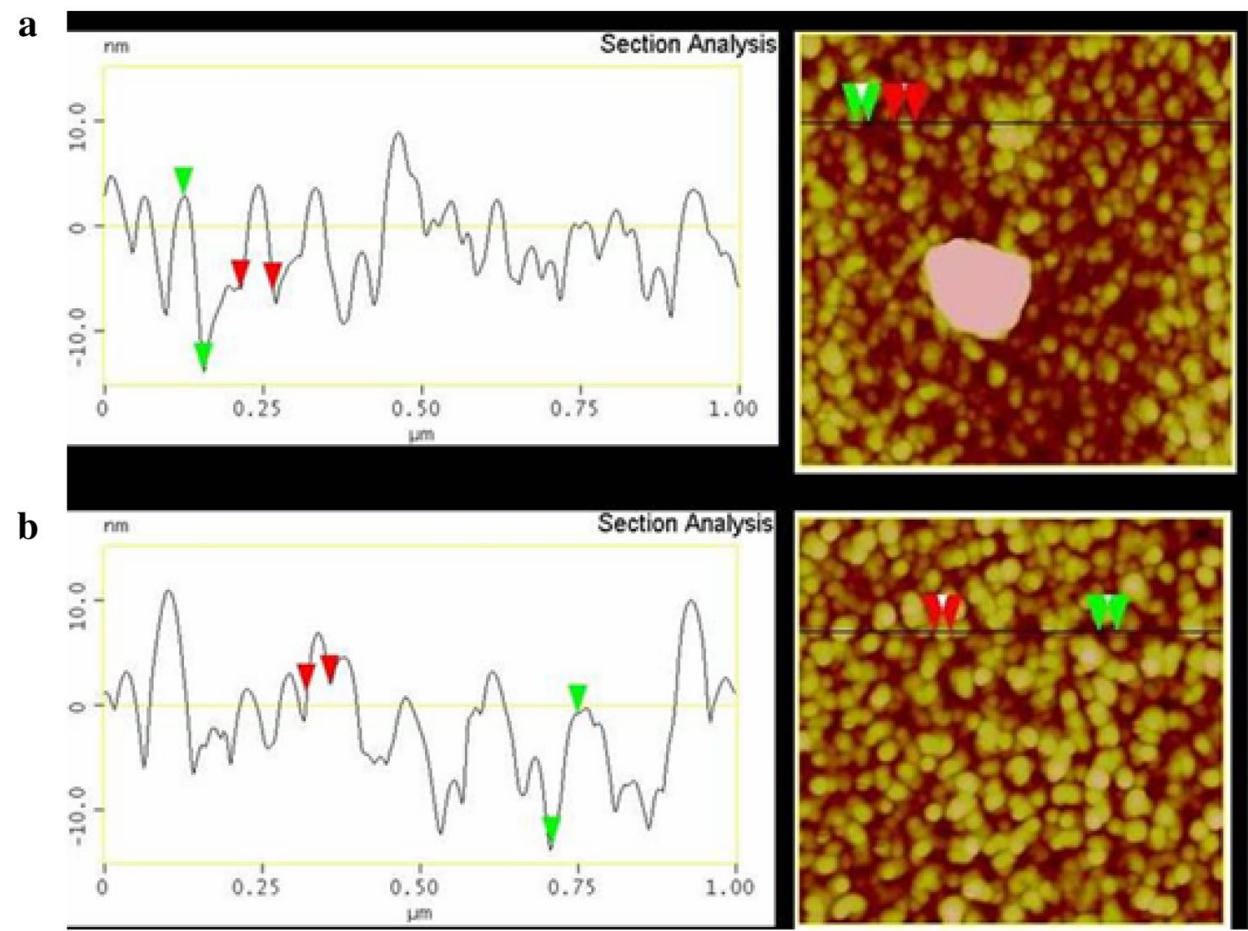

Fig. 1 AFM images of MP-nc-SiC (a), and HP-nc-SiC series films (b) 


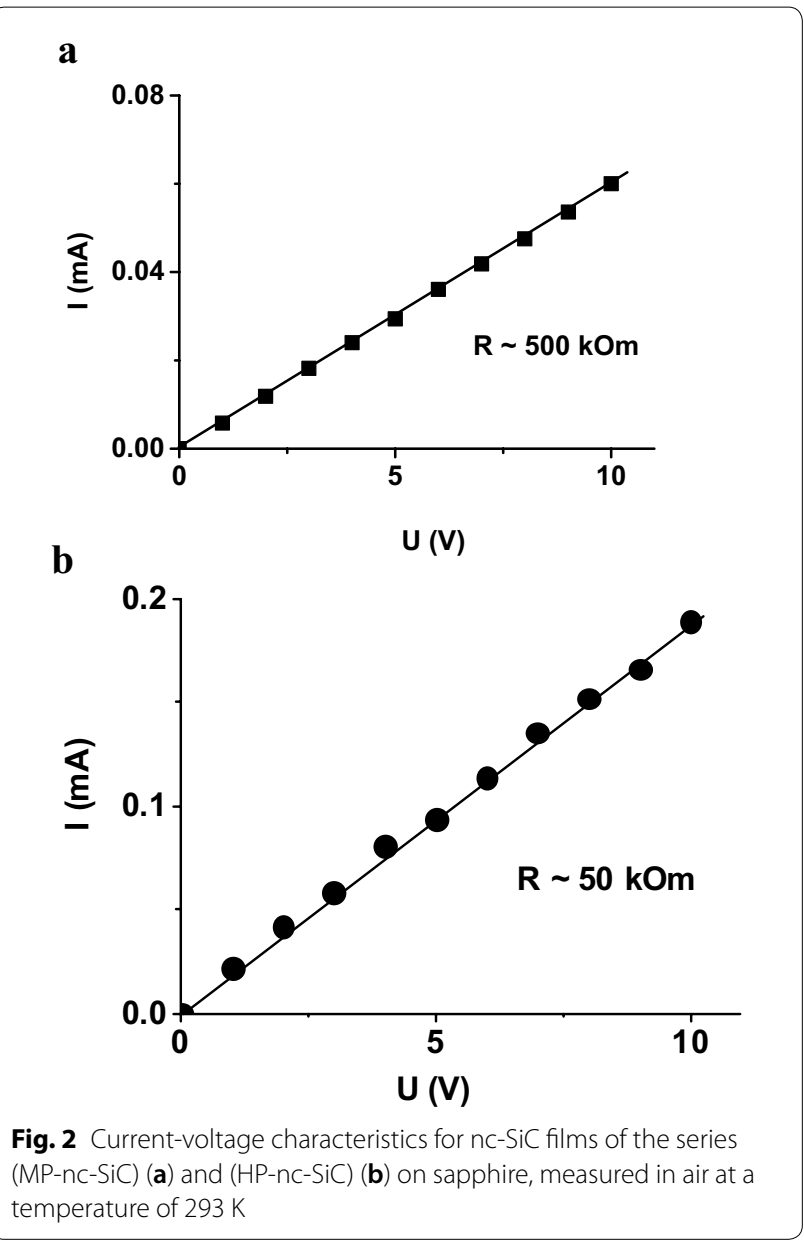

performed in a vacuum chamber so that they do not have contact with air before measurements.

It can be seen that the films not annealed in vacuum had almost identical conductivity characteristics in comparison with atmospheric measurements. This is probably due to the stable layer of chemisorbed gases that make up the atmospheric air formed on the surface of the films. It is known that the main contribution to atmospheric air belongs to $\mathrm{N}_{2}, \mathrm{O}_{2}$, as well as water vapor $\mathrm{H}_{2} \mathrm{O}$ and hydroxyl groups $\mathrm{OH}$. To restore a clean surface, the film must be annealed in vacuum at the desorption temperature of the corresponding gas. It is a fact of experiment that molecular gases and hydroxyl groups contained in the air are desorbed at temperatures up to $500 \mathrm{~K}$ [15]. The highest desorption temperature is for atomic oxygen forming the strongest bonds with the $\mathrm{SiC}$ surface.

Therefore, temperatures of 500 and $700 \mathrm{~K}$ were chosen for vacuum annealing. The graphs show that annealed films demonstrate an increase in conductivity with an increase in annealing temperature. This means that chemisorbed gases were the acceptors relative to the charge carriers in the zone of the surface conductivity

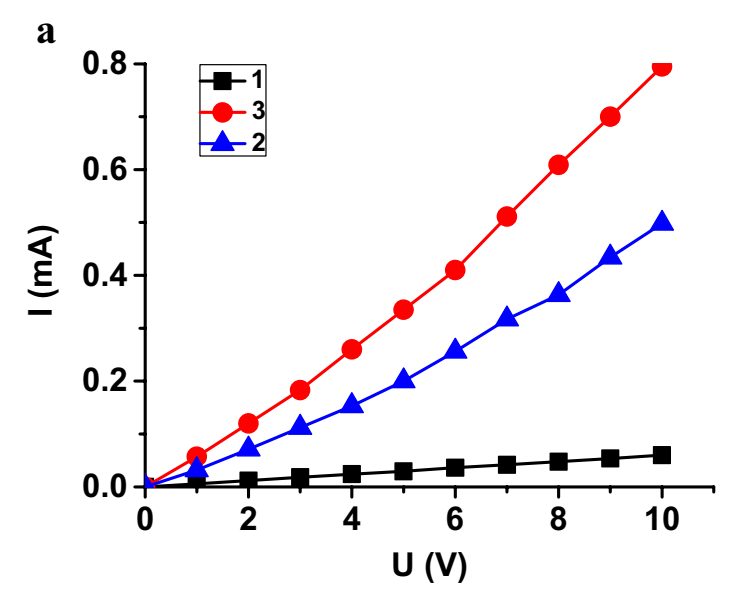

b

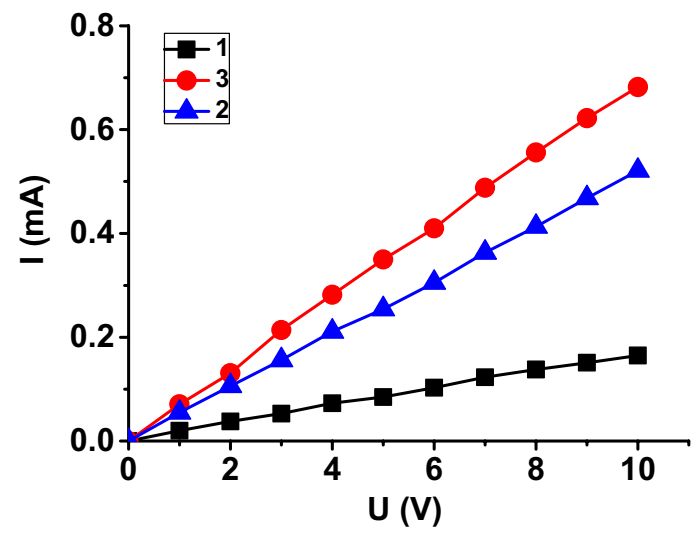

Fig. 3 Current-voltage characteristics of the MP-nc-SiC (a) and HP-nc-SiC (b) films measured in vacuum at $p<10^{-1} \mathrm{~Pa}$ at $293 \mathrm{~K}$ (1) and annealed in vacuum at $500 \mathrm{~K}(2)$ and $700 \mathrm{~K}(3)$

of $\mathrm{SiC}$, resulting in a conduction band worsening by the charge carriers-electrons. At this, the potential barrier to barrier conductivity was increased in the adsorption centers. During annealing, as the molecules of acceptors desorbed, electrons were released from the traps and filled the conduction band. Based on the literature [14] and obtained data on the temperature of the desorption of chemisorbed gases of atmospheric air, we have chosen $700 \mathrm{~K}$ as working temperature. At this temperature, the changes in the resistance of the films of both series in contact with the air atmosphere were measured. The measurements were carried out in a vacuum chamber of the VUP-5 unit with an initial pressure of $10^{-1} \mathrm{~Pa}$ at a dosed air inlet to atmospheric pressure in the region of sample with exposure to the complete relaxation processes of the electronic state of the system. To qualitatively determine the degree of activity of atmospheric gases $\mathrm{N}_{2}$ and $\mathrm{O}_{2}$ in the interaction with nc-SiC films, we also measured the electrical conductivity in an atmosphere of pure $(99,95 \%)$ nitrogen. The results of measurements of the dynamics 

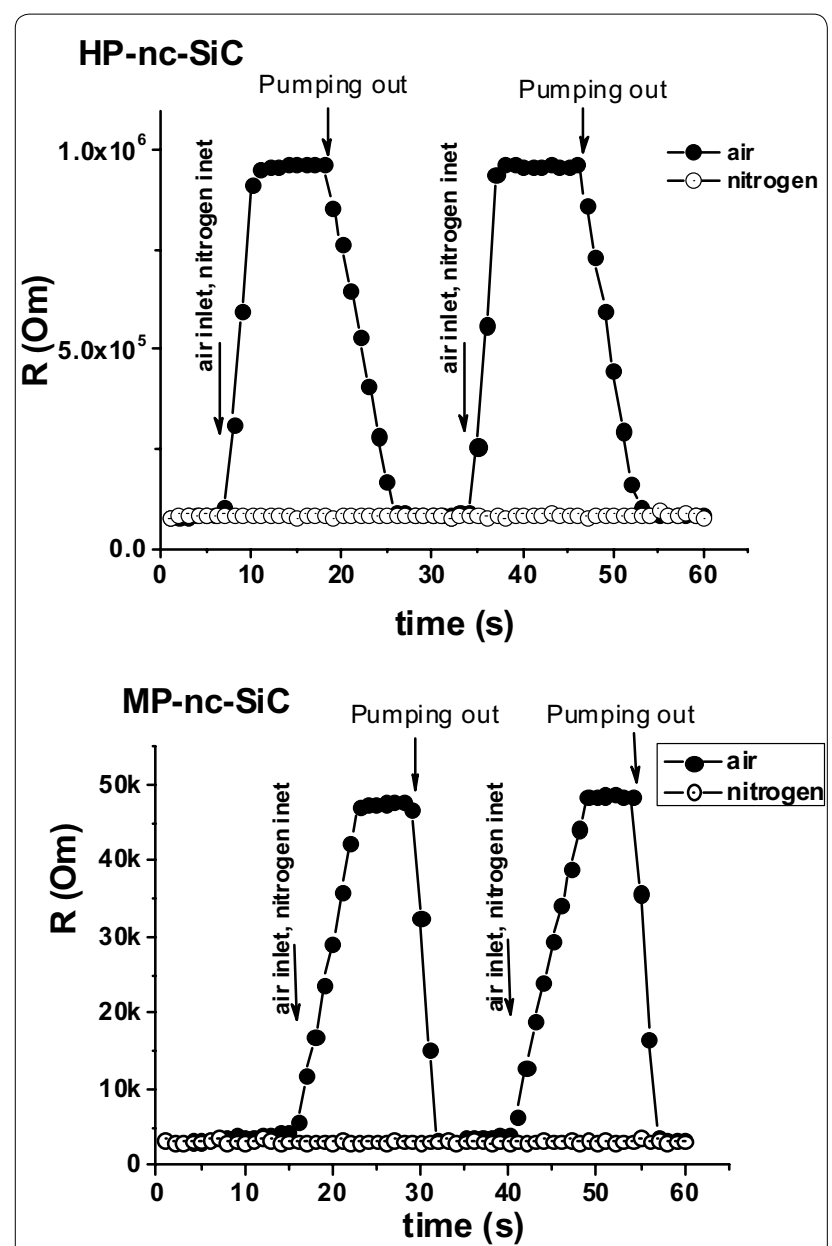

Fig. 4 The dependence of the electrical resistance of films of the series MP-nc-SiC (a) and HP-nc-SiC (b) on the interaction with air and pure nitrogen $(\mathrm{O})$ at atmospheric pressure, at a temperature of $700 \mathrm{~K}$

of film resistance changes (gas sensitivity characteristics) at a temperature of $700 \mathrm{~K}$ in response to atmospheric air and pure nitrogen are shown in Fig. 4.

It can be seen from the figure that the resistance of the films of both MP series (Fig. 3a) and the HP series (Fig. 3b) increased when air filled the chamber.

The figure shows that the resistance of the films of both series MP (Fig. 4a) and series HP (Fig. 4b) did not change substantially with filling pure nitrogen into the chamber to atmospheric pressure. This indicates that $\mathrm{O}_{2}$ plays the main role in the processes of the adsorption effect of atmospheric air on the conductivity of thin films. The increase in the resistance of films at the reaction to the oxidant gas is typical for films of n-type of electrical conductivity and is explained by the depletion of the surface layer of the film conductivity by charge carriers [16]. In this case, the film with hole conductivity should show the opposite reaction. The degree of increase of the resistance for films with mono- and heteropolytype structure was different. For monopolytype film, resistance increased for 12 times $(\mathrm{S}=91.6 \%)$, while heteropolytype film showed a resistance increase almost for 16 times $(S=93.7 \%)$. The thermoactivation mechanism of conductivity is observed in the monopolytype $\mathrm{SiC}$ layers, and the increase of resistance can be associated with the depletion of the conduction band by electrons, described by the linear function of the electron concentration. Multichannel conductivity is implemented in heteropolytype films, and the increase in resistance may be due to the increase in the height of the potential barrier between nanocrystals nc-3C-SiC/nc-21R-SiC. This dependence is expressed by an exponential function. Therefore, the heteropolytype structure of $\mathrm{nc}-\mathrm{SiC}$ films is more sensitive to the influence of chemisorbed gases with oxidative properties.. We believe that the gas that determines the change of film conductivity on the action of air is oxygen. A practically insignificant reaction to exposure to pure nitrogen (Fig. 4) confirms our assumption about the activity of oxygen on the surface of nc-SiC films in an air atmosphere.

\section{Conclusion}

The influence of the air atmosphere on the electrical conductivity of nanocrystalline thin $\mathrm{SiC}$ films obtained by method of direct ion deposition on sapphire was studied. Measurements were performed on two series of nc-SiC films with different structure: one series contained mainly $3 \mathrm{C}-\mathrm{SiC}$ polytype nanocrystals and were denoted as monopolytype, the second series were a nanoheterostructures based on a mixture of $3 \mathrm{C}-\mathrm{SiC}$ and $21 \mathrm{R}-\mathrm{SiC}$ nanocrystals. It is shown that the initial films of monopolytype series had greater resistance than heteropolype ones, and both series showed no reaction to changes in atmospheric pressure. Gas sensitivity of the films appeared after annealing in vacuum at temperatures above $500 \mathrm{~K}$. Measurements of the gas sensitivity of the films to the air atmosphere at a temperature of $700 \mathrm{~K}$ showed that the resistance increased for 12 times $(\mathrm{S}=91.6 \%)$ for the monopolytype film, while the heteropolytype film showed an increase of resistance for almost 16 times $(S=93.7 \%)$. We believe that it is possible to increase the efficiency of gas sensitivity of nc-SiC films by optimizing their structure. From a comparison of the effects of nitrogen and air on the conductivity of nc$\mathrm{SiC}$ films, we attribute the gas sensitivity of films to the adsorption of atmospheric oxygen.

Thus, the values of gas sensitivity of thin nc-SiC films were measured for the first time. The obtained results allowed to speak about the prospects of development of highly sensitive gas sensors on thin films of nanocrystalline $\mathrm{SiC}$. 


\section{Acknowledgements}

Thanks to Sergey Krivonosov of the Institute for Single Crystals NAS of Ukraine.

\section{Authors' contributions}

AS developed a method for producing nc-SiC films and proposed a concept for using them for sensors, and wrote the overall manuscript. AK performed measurements of the electrophysical characteristics of films and assisted in writing the manuscript. SS and DL performed the experiments for obtaining films and device fabrication. All authors read and approved the final manuscript.

\section{Funding}

This research did not receive any specific grant from funding agencies in the public, commercial, or not-for-profit sectors.

\section{Availability of data and materials}

The datasets supporting the conclusions of this article are included within the article.

\section{Ethics approval and consent to participate}

Not applicable.

\section{Competing interests}

The authors declare that they have no competing interests.

\section{Author details}

${ }^{1}$ National Technical University "Kharkiv Polytechnic Institute", 2, Kyrpychova Str., Kharkiv 61002, Ukraine. ${ }^{2}$ Institute for Single Crystals, NAS of Ukraine, Nauky Ave. 60, Kharkiv 61001, Ukraine.

Received: 26 February 2019 Accepted: 23 May 2019

Published online: 28 May 2019

\section{References}

1. Gopel W (1989) Solid-state chemical sensors: atomistic models and research trends. Sens Actuators 16:167-197. https://doi org/10.1016/0250-6874(89)80015-0

2. Rock F, Barsan N, Weimar U (2008) Electronic nose: current status and future trends. Chem Rev 108:705-725. https://doi.org/10.1021/cr068121q

3. Zorman CA, Parro RJ (2008) Micro- and nanomechanical structures for silicon carbide MEMS and NEMS. Phys Status Solidi B 245:1404-1424. https://doi.org/10.1002/pssb.200844135

4. Semenov AV, Puzikov VM, Dobrotvorskaya MV, Fedorov AG, Lopin AV (2008) Nanocrystalliine SiC films prepared by direct deposition of carbon and silicon ions. Thin Solid Films 516:2899-2905. https://doi. org/10.1016/j.tsf.2007.05.059
5. Hunter GW, Neudeck PG, Xu J, Lukco D, Trunek A, Artale M, Lampard P, Androjna D, Make D, Ward B, Liu CC (2004) Development of SiC-based gas sensors for aerospace applications. Mat Res Soc Symp Proc. 815:1-11

6. Ghosh RN, Loloee R, Isaacs-Smith T,. Williams JR (2005) High temperature reliability of SiC n-MOS devices up to $630^{\circ} \mathrm{C}$. Mat Sci Forum. Silicon Carbide and Related Materials. paper 3291

7. Gaiardoa A, Belluttib P, Fabbria B, Gherardia S, Gibertic A, Guidia V, Landinia N, Malagùa C, Pepponib G, Valtb M, Zontaa G (2016) Chemoresistive gas sensor based on $\mathrm{SiC}$ thick film: possible distinctive sensing properties between $\mathrm{H}_{2} \mathrm{~S}$ and $\mathrm{SO}_{2}$. Procedia Eng 168:276-279. https://doi. org/10.1016/j.proeng.2016.11.191

8. Kozlovskyi A, Semenov A, Skorik S (2016) Electron transport in nanocrystalline SiC films obtained by direct ion deposition. Superlattices Microstruct 100:596-604. https://doi.org/10.1016/j.spmi.2016.10.013

9. Semenov AV, Lopin AV, Puzikov VM, Boriskin VN (2009) Effect of irradiation on the properties of nanocrystalline silicon carbide films. Semiconductors 43(10):1322-1327. https://doi.org/10.1134/S106378260910011X

10. Mitin VF, Kholevchuk W, Semenov AV, Kozlovskii AA, Boltovets NS, Krivutsa VA, Slepova AS, Novitskii SV (2018) Nanocrystalline SiC film thermistors for cryogenic applications. Rev Sci Instrum 89(2):025004-1-025004-5. https://doi.org/10.1063/1.5024505

11. Semenov AV, Puzikov VM, Golubova EP, Baumer VN, Dobrotvorskaya MV (2009) Low-temperature production of silicon carbide films of different polytypes. Semiconductors. 43(5):685-689. https://doi.org/10.1134/S1063 782609050273

12. Semenov AV, Lopin AV, Puzikov VM, Baumer VN, Dmitruk IN (2010) Fabrication of heterostructures based on layered nanocrystalline silicon carbide polytypes. Semiconductors 44:816-823. https://doi.org/10.1134/ S1063782610060229

13. Choyke WJ, Matsunami H, Pensl G (2004) Silicon carbide: recent major advances, vol 1. Springer, Berlin

14. Kao K, Huang V (1971) Transfer of electrons in solids t.t.1 2, Hardcover

15. Golovanov V, Mäki-Jaskari M, Korotcenkov G, Brinzari V, Cornet A, Morante $J$ (2005) Experimental and theoretical studies of indium oxide gas sensors fabricated by spray pyrolysis. Sens Actuators B 106:563-571. https://doi. org/10.1016/j.snb.2004.07.026

16. Volkenshtein FF (1987) Electron processes on the surface of semiconductors during chemisorption. -M.: Science

\section{Publisher's Note}

Springer Nature remains neutral with regard to jurisdictional claims in published maps and institutional affiliations.

\section{Submit your manuscript to a SpringerOpen ${ }^{\circ}$ journal and benefit from:}

- Convenient online submission

- Rigorous peer review

- Open access: articles freely available online

- High visibility within the field

- Retaining the copyright to your article

Submit your next manuscript at $\boldsymbol{\nabla}$ springeropen.com 